\title{
Kaolin Dağılımının Spektral Sınıflama Yöntemleri ile Belirlenmesi: Geminbeli Kaolin Yatağı (Sivas) ve Çevresi
}

\author{
Determination of Kaolin Distribution by Using Spectral Classification Methods: Geminbeli \\ Kaolin Deposit (Sivas) and Its Surroundings
}

\author{
Oktay CANBAZ*1,a, Önder GÜRSOY ${ }^{2, b}$, Ahmet GÖKCE ${ }^{1, c}$ \\ ${ }^{1}$ Cumhuriyet Üniversitesi, Mühendislik Fakültesi, Jeoloji Mühendisliği Bölümü, 58140, Sivas \\ ${ }^{2}$ Cumhuriyet Üniversitesi, Mühendislik Fakültesi, Harita Mühendisliği Bölümü, 58140, Sivas
}

• Geliş tarihi / Received: 29.04.2020 • Düzeltilerek geliş tarihi / Received in revised form: 30.08.2020 • Kabul tarihi / Accepted: 20.09 .2020

\begin{abstract}
Öz
Kaolin grubu killer, günümüzde kağıt, çimento, boya, ilaç, seramik ve plastik sanayisi gibi oldukça geniş kullanım alanlarına sahiptirler. Türkiye' de özellikle çimento ve seramik sanayisinin yüksek ekonomik değerli hammaddesini oluşturmaktadır. Bu tür sahaların tespiti ve halihazırda işletilenlerin ise iyileştirilmesi için arazi ve laboratuvar süreçleri oldukça önemlidir. Son yıllarda, uydu verileri ile mineral haritalama çalışmaları yapılmakta olup madencilik sektörüne katk1 sunacak olumlu sonuçlar ortaya çıkmaktadır. Bu çalışma, uydu verilerinin yoğun killeşme alanlardaki performansını belirlemeye yönelik gerçekleştirilmiş̧ir. İnceleme alanı, Sivas ili Zara ve Suşehri ilçeleri arasında kalan bölgede mevcut bir kaolin işletmesi ve çevresini kapsamaktadır. Araziden alınan temsili örnekler de yapılan petrografik ve XRD incelemelerinde, kaolinit, illit, smektit ve klorit kil türleri tespit edilmiştir. Çalışmada, ASTER uydu görüntüsüne Spektral Açı Haritalama (SAM) ve Eşlenen Filtreleme (MF) spektral sinıflandırma yöntemleri uygulanarak, killeşme gösteren alanlarda kaolinit, illit, smektit ve klorit dağılımları ortaya çıkarılmıştır. Kaolinit için, uydu verilerinden elde edilen sonuçlar ile arazi verilerinin yüksek oranda örtüştüğü belirlenmiştir. Ayrıca MF yönteminin, illit, klorit ve smektit dağılımlarının belirlenmesinde SAM yöntemine göre daha iyi sonuçlar verdiği görülmüştür.
\end{abstract}

Anahtar kelimeler: Eşlenen Filtreleme, Hidrotermal Alterasyon, Kaolin Yatağı, Spektral Açı Haritalama, Spektral Siniflama

\begin{abstract}
In the nowadays, kaolin group clays have a wide range of areas of utilization such as paper, cement, paint, pharmaceutical, ceramic and plastic industries. It is a raw material with high economic value in especially cement and ceramic industries in Turkey. The field and laboratory processes are crucial for the detection of such sites and for the improvement of already mining operated sites. In recent years, mineral mapping studies have been carried out with satellite data and useful results have obtained that contribute to the mining process. In this study, it was carried out to determine the performance of satellite data in argillisation areas. The study area is located between Zara and Suşehri Towns of Sivas Province and include a kaolin deposit. In the petrographic and XRD investigations, which were also carried out in representative samples taken from the study area, kaolinite, illite, smectite and chlorite clays were determined. In the study, kaolinite, illite, smectite and chlorite distributions were determined by using the SAM (Spectral Angle Mapper) and MF (Matched Filtered) spectral classification methods in the argillization areas. For kaolinite, it has been determined that the results obtained from satellite data substantially coincided with the field study data. Furthermore, it has been observed that MF method gives better results in illite, chlorite and smectite distributions than SAM method.
\end{abstract}

Keywords: Matched Filtering, Hydrothermal Alteration, Kaolin Deposit, Spectral Angle Mapper, Spectral Classification

\footnotetext{
*a Oktay CANBAZ; ocanbaz@ cumhuriyet.edu.tr, orcid.org/0000-0002-8161-1326

${ }^{\mathrm{b}}$ orcid.org/0000-0002-1531-135X $\quad{ }^{\mathrm{c}}$ orcid.org/0000-0001-7776-1893
} 


\section{Giriş}

Hidrotermal alterasyonlar, özellikle porfiri tipi, damar tipi, volkanojenik masif sülfid ve epitermal maden yatakları çevresinde bu yatakları oluşturan çözeltilerce meydana gelirler (Pirajno, 2009). Bu oluşumlar $\mathrm{OH}$ - içeren mineraller, sülfatlar, karbonatlar, demir oksitler ve hidroksitler gibi belirli mineral parajenezine sahiptirler (Pirajno, 2009). Parajenezi oluşturan bu mineraller kendilerine ait $0.4-1.0,1.3-2.5$, and 8.014.0 aralıklarında değişen elektromanyetik spektral özelliklere sahiptirler (Clark, 1999; Gupta, 2003). Bu özellikleri, uydu verilerinde görüntü işleme ve spektral sınıflama yöntemleri kullanılarak kendilerine ait dağılım haritaları belirlenmesinde ve litolojik özelliklerin ortaya çıkarılmasında önemli bir rol oynamaktadırlar. Elde edilen sonuçlarda, değerli maden yataklarının aranmasında hedef sahaların belirlenmesine öncülük edebilmektedirler.

Son yıllarda, birçok araştırmacı tarafindan Advanced Spaceborne Thermal Emission and Reflection Radiometer (ASTER), Landsat, Sentinel 2A, Hyperion ve WorldView-3 (WV-3) gibi multispektral ve hiperspektral uydu görüntülerinden yararlanılarak bu tür sahalarda litolojik birimlerin ve hidrotermal alterasyon minerallerinin belirlenmesine yönelik çalışmalar gerçekleştirmiştir (Gad ve Kusky 2007; Yang vd., 2012; Kruse, 2012; Pour ve Hashim 2012; Kruse ve Perry, 2013; Ayoobi ve Tangestani 2017; Mahanta ve Maiti 2018; Hu vd., 2018; Canbaz vd., 2018; Rajedran ve Nasir, 2018; Abrams ve Yamaguchi, 2019; Salehi ve Tangestani, 2020).

$\mathrm{Bu}$ çalışmada kullanılan ASTER uydusuna ait multispektral görüntü, 0.52 ile $0.86 \mu \mathrm{m}$ bant aralığına sahip 3 adet Görünür Bölge Yakın Kızılötesi Radyometre (VNIR), 1.6 ile $2.43 \mu \mathrm{m}$ bant aralığına sahip 6 adet Kısa Dalga Kızıl Ötesi Radyometre (SWIR) ve 8.125 ile $11.65 \mu \mathrm{m}$ bant aralığına sahip 5 adet Termal Kızıl Ötesi Radyometre (TIR) bölgelerini kapsayan bantlardan oluşmaktadır. ASTER uydusu SWIR bantları, özellikle hidrotermal alterasyon alanlarında mineralleri tanımada oldukça yüksek potansiyele sahiptirler (Abrams ve Hook, 1995). Bu nedenle, çalışmanın konusunu oluşturan kaolin kil türünün bölgedeki dağılımını belirlemek için SWIR bantlarından yararlanılmıştır.

Killer, genellikle feldispat, mika, kuvars ve demir oksitlerin yüzeysel ve/veya hidrotermal koşullar altında bozunmasıyla oluşmakta olup çok karmaşık bir mineral yapısına sahiptirler.
Kimyasal içerikleri, yapısal ve mineralojik özelliklerine göre kaolin, smektit (montmorillonit), illit, klorit ve diğer (sepiyolit veya attapulgit) gruplara ayrlmaktadırlar (Malayoğlu ve Akar, 1995). Kaolin grubu killerin, ana hammaddesini feldispatların bozunması ile oluşan alümina hidrosilikat minerali olan kaolinit $\left(\mathrm{Al}_{2} \mathrm{Si}_{2} \mathrm{O}_{5}(\mathrm{OH})_{4}\right)$ oluşturmakta olup bununla birlikte oluşum ortamında bulunan mika, kuvars ve demir oksitlerden türemiş kil minerallerini de içerebilmektedirler (Malayoğlu ve Akar, 1995). Oluşum şekli ve ortamına göre hidrotermal, rezidual ve sedimanter kaolin yatakları şeklinde ayrılmaktadırlar (URL-1). MTA (Maden Tetkik ve Arama Müdürlüğü) tarafindan yapılan araştırmalar, Türkiye'deki kaolin yataklarının büyük bir bölümünün hidrotermal kökenli olduğunu göstermektedir. Kaolin yatakları, kâğıt, çimento, boya, ilaç, seramik ve plastik gibi birçok sanayi alanında yüksek ekonomik değere sahip hammaddeyi oluşturmaktadır. Dünyada, özellikle kağıt üretiminde ilk sirayı almakta olup Türkiye'de ise çoğunluğu çimento ve seramik üretiminde kullanılmaktadır. $\mathrm{Bu}$ kadar geniş kullanım alanına sahip olan kaolinleri içeren sahaların tespiti ülke ekonomisi açısından oldukça önemlidir.

$\mathrm{Bu}$ çalışma, Sivas ili Zara ve Şuşehri ilçeleri arasında kalan bölgede, hidrotermal çözelti faaliyetleri sonrasında yoğun hidrotermal alterasyon içeren siyenitik ve volkanik kayaçlarla kaplı sahada, kaolin potansiyelini belirlemeye yönelik gerçekleştirilmiştir. Yapılan bu çalışmada spektral siniflandirma yöntemlerinden yararlanılmıştır. Çalışma sonucunda elde edilen verilerin, gerek halihazırda işletilen Geminbeli kaolin sahasının geliştirilmesinde gerekse de yeni kaolin sahalarının keşfine yönelik yapılacak çalışmalardaki katkıları değerlendirilmiştir.

\section{Jeolojik Özellikler}

İnceleme alan1, Neo-Tetis okyanusun kapanmas1 sonrasında gelişen İzmir-Ankara-Erzincan Sütur Zonunun üzerinde yeralmaktadır (Şekil 1). Bölgenin temelini Paleozoyik yaşlı Tokat Metamorfitleri ile bunları tektonik dokunak ile üzerleyen Mesozoyik yaşlı Refahiye Ofiyolitli Karmaşığı oluşturmaktadır. Birim, volkanik ara katkıl1 kumtaş1-siltaş1 ardalanmas1 gösteren Akıncılar Formasyonu tarafindan uyumsuz olarak örtülmektedir (Yılmaz vd., 1985). İnceleme alanı sınırları içinde kalan ve yoğun killeşme gösteren Eosen yaşlı Karataş Volkanitleri ile Lütesiyen yaşlı Kösedağ Siyeniti ise bu birimleri keserek bölgeye yerleşmişlerdir (Kalkanc1, 1974; Yılmaz 
vd., 1985; Başıüyük, 2006; Boztuğ, 2008; Eyuboglu vd., 2017) (Şekil 2).

Kösedă Siyeniti ve Karataş Volkanitleri, inceleme alanı ve çevresinde saçınımlı ve damar tipi $\mathrm{Cu}-\mathrm{Pb}-\mathrm{Zn} \pm \mathrm{Au}$ hidrotermal zenginleşmeleri içeren yankayaçları oluşturmaktadırlar (Efe ve Gökce, 1999; Canbaz vd., 2018). Bu cevherleşmeleri oluşturan çözeltiler aynı zamanda, siyenit ve volkaniklerden oluşan yan kayaçlarda yoğun killeşme, kloritleşme ve limonitleşme/hematitleşme gibi hidrotermal alterasyonlara neden olmuştur. Killeşmelerin, bu yankayaçların özellikle kırık ve çatlak sistemlerinde yoğunlaştı̆̆ gözlenmekte olup yer yer masif pirit oluşumları içerdikleri arazi çalışmalarında gözlenmiştir (Şekil 3).

\section{Materyal ve Metod}

\subsection{Arazi ve Laboratuvar Çalıșmaları}

Yoğun bitki örtüsünün hakim olduğu bölgede, arazinin sarp ve engebeli olması nedeniyle örneklemeler ulaşımı kolay bölgelerden yapılmıştır (Şekil 2). Çalışmada, özellikle killeşme türü alterasyon gösteren alanlardan temsili 30 adet örnek toplanmıştır. Bu örneklerden incekesit hazırlanabilenlerin mikroskobik incelemeleri Leica DM 2500 alttan ve üstten aydınlatmalı polarizan mikroskop ile gerçekleştirilmiştir. Kil ayrıştırma yöntemi gerçekleştirilecek örneklerin, kil ve mineral içeriğini belirlemek amaçlı tüm kayaç X-Ray Difraktomları (XRD-TK) çekilmiştir. Kil içeriğinin yoğun ve kil elde edilebilecek 10 örnekte ise kil ayırma işlemleri gerçekleştirilmiş olup kil fraksiyon X-Ray Difraktomları (XRDKF) çekilmiştir. Kil ayırma, kırma ve ögütme işlemlerinden sonra toz numune haline getirilen örneklerin, kimyasal çözme, santrifüj, dekantasyon, dinlendirme, yıkama ve sifonlama gibi işlemlerden geçirilmesi ile gerçekleştirilmiştir. Kil fraksiyonları için üç farklı preparat kesit hazırlamıştır. Bunlar, normal (oda koşullarında su içeriği uzaklaştırılmış), glikollü (ortalama $60^{\circ} \mathrm{C}^{\prime} \mathrm{de}$ desikatör içerisinde etilen glikol buharında bekletilmiş) ve firınlanmış (490 ${ }^{\circ} \mathrm{C}$ 'de yaklașık 4 saat 1sıtma ișleminden geçirilmiș) preparatlar şeklindedir. XRD çekimleri Rigaku marka DMAX IIIC model X-1şınları difraktometresinde $($ Anot $=1.541871 \AA)$, Filtre $=$ $\mathrm{Ni}$, Gerilim $=35 \mathrm{kV}, \mathrm{Ak} 1 \mathrm{~m}=15 \mathrm{~mA}$, Gonyometre hızı $=2 \%$ dak., Kağıt hızı $=2 \mathrm{~cm} /$ dak., Zaman sabiti $=1 \mathrm{sn}$, Yarıklar $=1^{\circ} 0.15 \mathrm{~mm} 1^{\circ} 0.30 \mathrm{~mm}$, Kağıt aralığ $1=2 \theta=5-35^{\circ}$ ) olacak şekilde gerçekleştirilmiştir.

Hidrotermal alterasyon mineralojisi ve kil tayini yapılan örneklerin spektral imza ölçümleri Analytical Spectral Devices (ASD) Fieldspec Pro spektroradyometre cihazı ile gerçekleştirilmiştir. Tüm laboratuvar çalışmaları Sivas Cumhuriyet Üniversitesi Jeoloji ve Harita Mühendisliği Bölümlerinde yapılmıştır. Sinıflandırma yöntemlerinde kullanılmak üzere kaolinit ve illit spektral imzaları ile USGS kütüphanesinden alınan smektit ve klorit yansıma değerleri, ASTER SWIR bant aralığına yeniden örneklenmiştir (Şekil 4).

\subsection{Uydu Verisi}

Çalışmada, 16.08.2005 tarihli ASTER L1B uydu görüntüsünün SWIR bantları kullanılmıştır. SWIR bantları, bölgesel ölçekte litolojik özelliklerin ortaya çıkarılmasında kullanıldığı gibi $\mathrm{Al}-\mathrm{OH}$, $\mathrm{Mg}-\mathrm{OH}, \mathrm{Si}-\mathrm{O}-\mathrm{H}, \mathrm{FeOX}$ ve $\mathrm{CO}_{3}$ gibi hidrotermal alterasyon minerallerinin tespiti ve dağılımlarının tayininde de kullanılmaktadır (Hunt, 1977; Abrams ve Hook, 1995; Yamaguchi vd., 1998; Abrams, 2000). ASTER uydu görüntüleri, algilayacı yapısından kaynaklanan hatalar ile atmosferik etkilerden olumsuz olarak etkilenmektedirler. ASTER L1B uydu görüntüleri atmosferik düzeltmeler yapılmadan üretilirler (Abrams, 2000). Spektral sinıflama yöntemlerinde elde edilen sonuçların doğruluğunu artırmak için bu hataların giderilmesi ve atmosferik etkilerinin ortadan kaldırılması gerekmektedir. Bu etkileri ortadan kaldırmak için görüntüde çapraz karışım düzeltmesi (Cross-Talk), radyans kalibrasyonu ve atmosferik düzeltme gibi işlemler gerçekleştirilmiştir. Çapraz karışım düzeltme işlemi için ERSDAC yazılımı kullanılmıştır. Yazılım, Iwasaki ve Tonaka (2005) tarafindan önerilen bağıntıyı otomatik olarak uygulamaktadır. Radyans kalibrasyonu, Abrams ve Hook (1995) bağıntısı kullanılarak gerçekleştirilmiştir. Atmosferik düzeltmede ise Achard ve D'Souza (1994) ile Eva ve Lambin, (1998) bağıntısı kullanılmıştır. Bu her iki işlemde de ER MAPPER yazılımı kullanılmış olup görüntüye ait bantlara tek tek uygulanmıştır. 


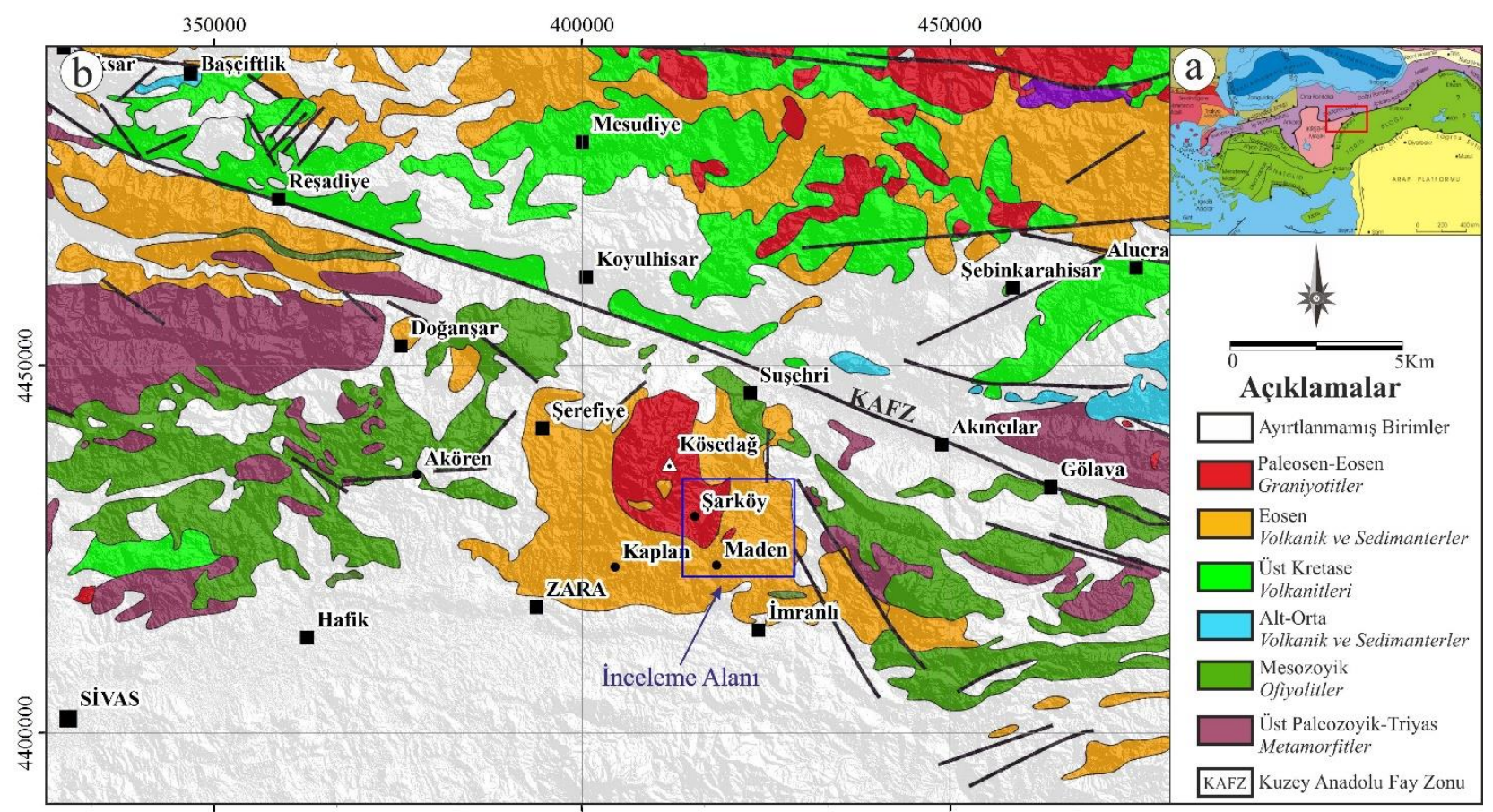

Şekil 1. (a) Türkiye' nin ana suturları ve kıtasal blokları gösteren tektonik haritası (Okay ve Tüysüz, 1999). (b) Bölgesel jeoloji haritası (MTA, 2002' den revize edilerek hazırlanmıştır)

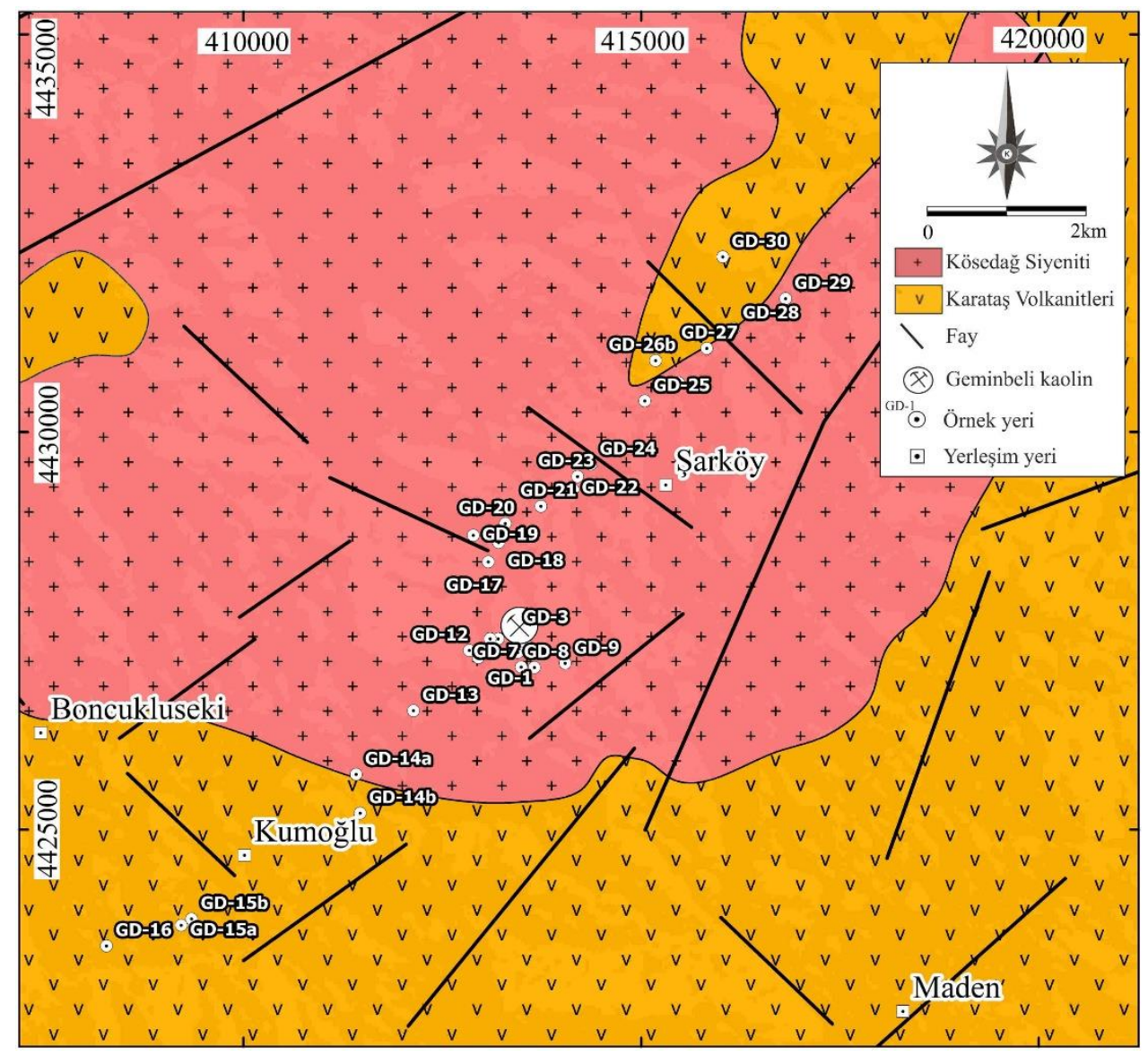

Şekil 2. İnceleme alanı yerel jeoloji haritası (Kalkanc1, 1974; Y1lmaz vd.,1985; MTA, 2002; Başıbüyük, 2006; ve Canbaz vd., 2018) 'den revize edilerek hazırlanmıştır) 

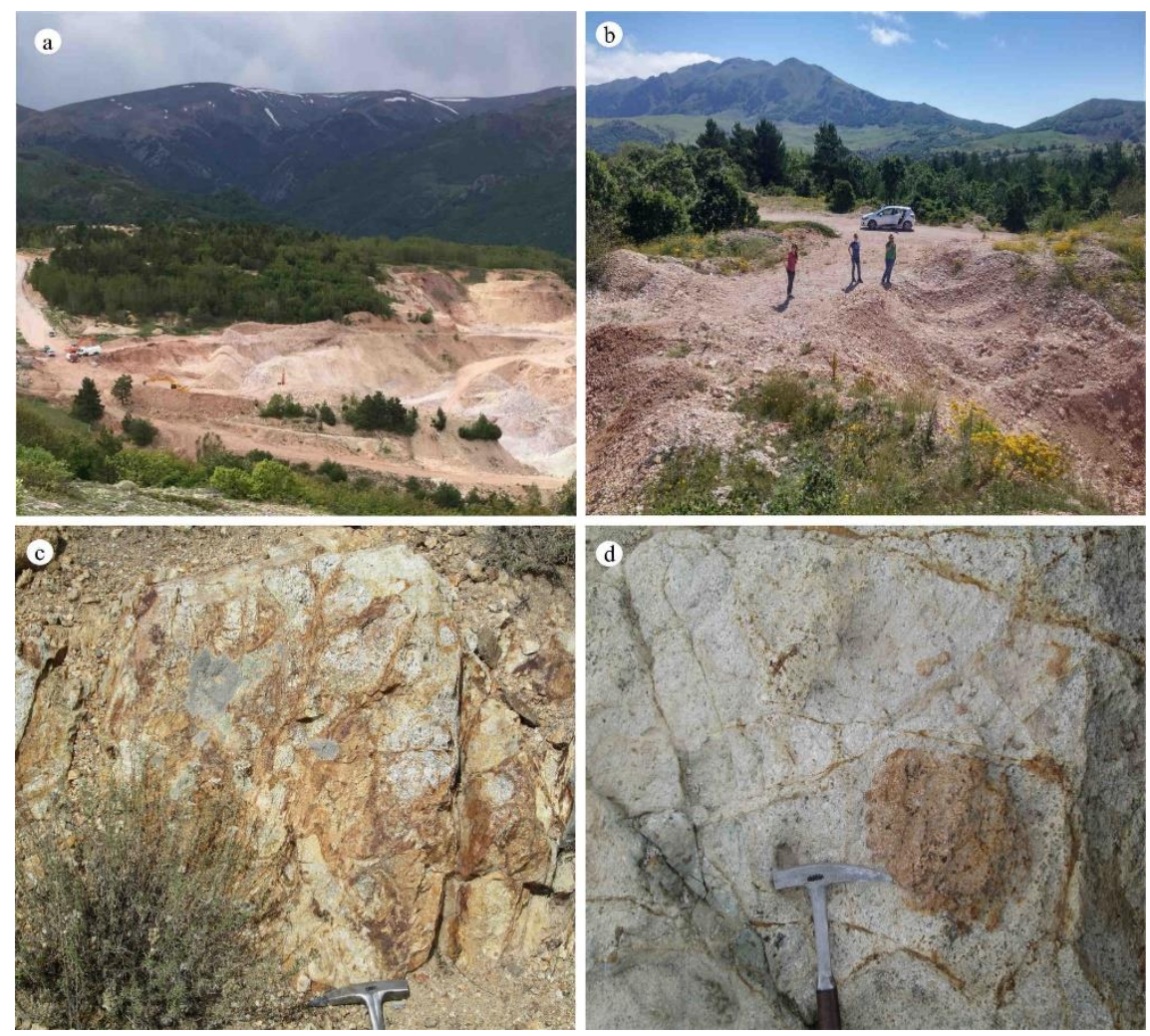

Şekil 3. (a) Geminbeli kaolin yatağı işletme alanı görünümü. (b) GD-12 nolu örnek lokasyonuna ait görünüm. (c-d) Kırık ve çatlak sistemlerinde killeşme görüntüleri

\subsection{Spektral Sınıflama Yöntemleri}

$\mathrm{Bu}$ çalışmada, litolojik ve mineralojik farklılıkların ortaya çıkarılmasında yaygın olarak kullanılan Spektral Açı Haritalama (SAM) ve Eşlenen Filtreleme (MF) spektral sinıflama yöntemlerinden yararlanılmıştır. Çizim ve uydu verilerinin değerlendirilmesinde ENVI 5.3 ve ARCGIS yazılımları kullanılmıştır.

SAM, iki Nesne Tabanlı Referans Spektral (NTRS) arasındaki benzerlik derecesinin kullanıldığı bir sinıflama yöntemidir. Yöntem, spektral yansıtım verilerine göre oluşturulan referans vektörü ile uydu görüntüsü piksel değerlerinden meydana gelen vektör ile sinıfı bilinmeyen piksel değerleriyle oluşturulan vektör arasındaki açının hesaplanmasıyla uygulanır (Hawkesworth vd., 1997; Rowan vd., 2005; Massironi vd., 2008). Hedef yansitma özelliklerinin vurgulanarak açı̆̆a çıkarılmasında gölgeleme etkilerini ortadan kaldırır (De Carvalho ve Meneses, 2000). Görüntü spektrumlarının spektral benzerliğini referans olarak verilen spektrumlara kolay ve hızlı eşlemek en temel avantajlarından bir tanesidir. $\mathrm{Bu}$ yöntemde ki temel dezavantaj ise elde edilen referans spektrumun saf olduğu varsayımı olup bu durum yöntemin eksik ve/veya fazla siniflandirma yapmasına neden olmaktadır (Girouard vd., 2004).
MF, mineral olasılığını tahmin edebilmekle birlikte mineral ayrımı için tespit edilebilirlik ve seçicilik sunan spektral sınıflandırma yöntemlerinden bir tanesidir (Boardman, 1998).Yöntem de referans olarak gösterilen spektral yansıma ölçümlerinin bolluk oranına göre siniflama yapılmakta olup referansa ait yansımalar en üst düzeye çıkarılarak, ilgisiz yansımaların ise bastırılmasıyla sonuç elde edilmektedir (Harsanyi ve Chang, 1994; Boardman, 1998; Mehr vd., 2013). MF spektral sinıflandırma yöntemi, spektral kütüphaneye dayalı olarak hızlı bir şekilde sonuç elde edilmesini sağlamaktadır. Bu yöntemin en önemli sorunlarından bir tanesini karışık piksel problemi oluşturmaktadır.

\section{Bulgular}

Killeşme gösteren alanlardan toplanan örneklerde yer yer pirit mineralleri makroskopik olarak gözlenebilmektedir. Petrografik inceleme yapılabilecek özellikte olan ve killeşme gösteren örneklerde eser miktarda kuvars içeriği saptanmıştır. Yine bu örneklerde yapılan XRDTK çekimlerinde ise, kuvars, feldispat, amfibol, piroksen, epidot, kalsit, klorit, hematit, muskovit, jips ve kil pikleri tespit edilmiştir (Şekil 5). Kaolin işletmesi ve yakın çevresinden alınan XRD-KF çekimleri yapılmış örneklere ait sonuçlar Çizelge 
1'de verilmiştir. İşletme içerisinden ve yakın çevresinden alınan örneklerde kaolinit hakim olup az da olsa illit oluşumları gözlenmiştir (Şekil 6). İşletmeden uzak alanlardan alınan bazı örneklerde ise illit, smektit ve klorit içeriği saptanmıştır.

XRD-KF sonuçlarına göre, geniş yayılım gösteren bu yoğun hidrotermal alterasyonlu bölgelerde gelişen killeşmeler çeşitlilik göstermektedir. Bu çeşitliliği ortaya çıkarmak ve dağılımlarını belirlemek amaçlı SAM ve MF spektral sınıflama yöntemleri kullanılmıştır. Belirlenen kil grubu minerallere ait spektral imzalar bu yöntemler de ayrı ayrı uygulanmıştır. Elde edilen sonuçların uzaysal dağılımları ve coğrafik konumları uydu görüntüsü üzerinde gösterilmiştir (Şekil 7).
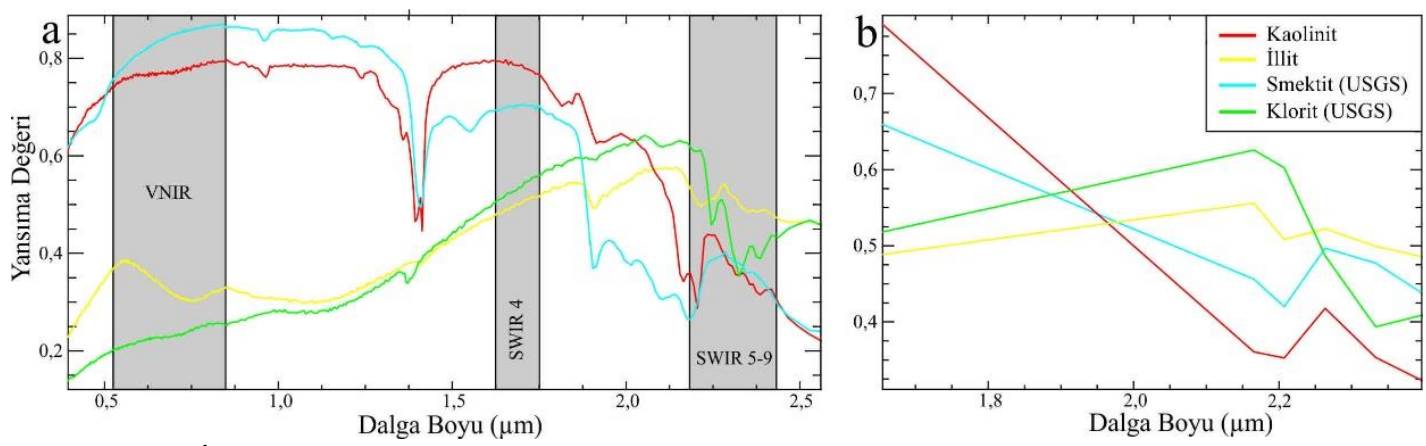

Şekil 4. (a) İnceleme alanında dağılım gösteren alterasyon minerallerinin spektral yansıma değerleri (smektit ve klorit spektral yansıma değerleri USGS (Amerika Birleşik Devletleri Jeoloji Araştırmaları Kurumu) kütüphanesinden alınmıştır). (b) ASTER SWIR bant aralığına yeniden örneklenmesi

Tablo 1. İnceleme alanı temsili örneklerde XRD-KF çekim sonuçlarında kil dağılımları

\begin{tabular}{|l|c|c|c|c|}
\hline Örnek & Kaolinit & \multicolumn{1}{|l|}{ Illit } & Smektit & Klorit \\
\hline GD-3 & + & + & - & - \\
\hline GD-8 & + & + & - & - \\
\hline GD-12 & + & + & - & - \\
\hline GD-13 & + & + & - & - \\
\hline GD-16 & + & + & - & - \\
\hline GD-18 & + & + & - & - \\
\hline GD-21 & + & + & - & - \\
\hline GD-14a & + & + & - & - \\
\hline GD-15b & + & + & + & + \\
\hline GD-23 & + & + & + & + \\
\hline GD-27 & - & + & - & + \\
\hline GD-29 & + & + & + & + \\
\hline
\end{tabular}

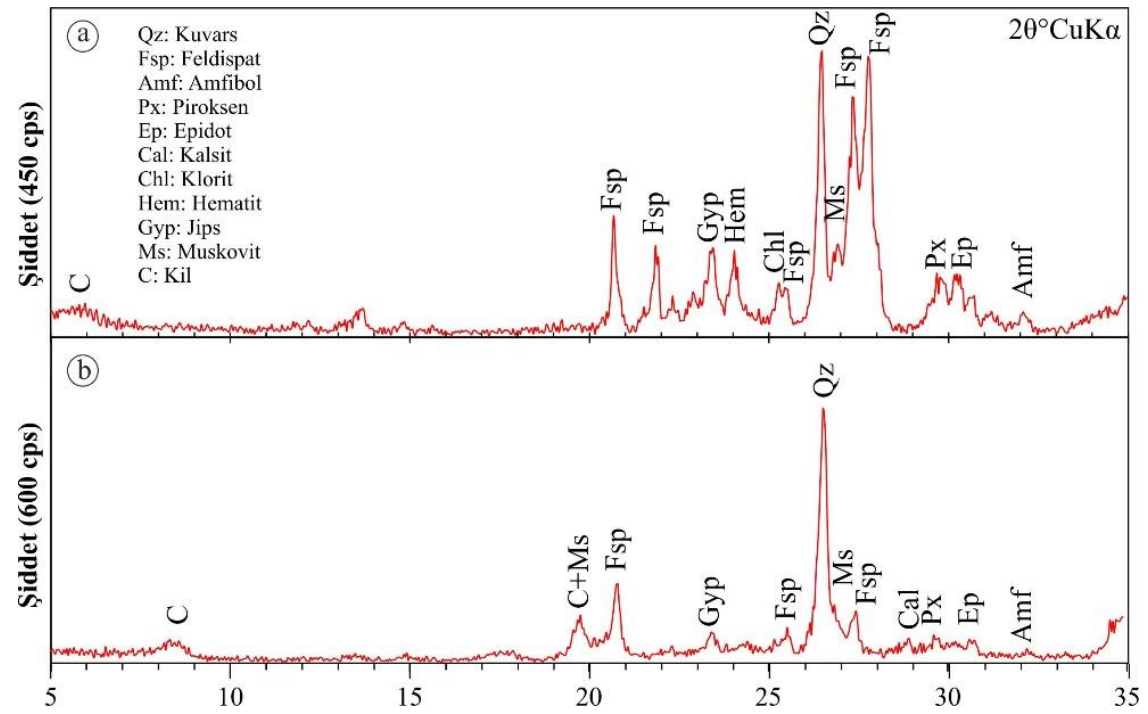

Şekil 5. Killeşme gösteren kayaç gruplarında XRD-TK çekimi. (a) Altere siyenit örneği (örnek no: GD-20). (b) Altere volkanit örneği (örnek no: GD-16) 


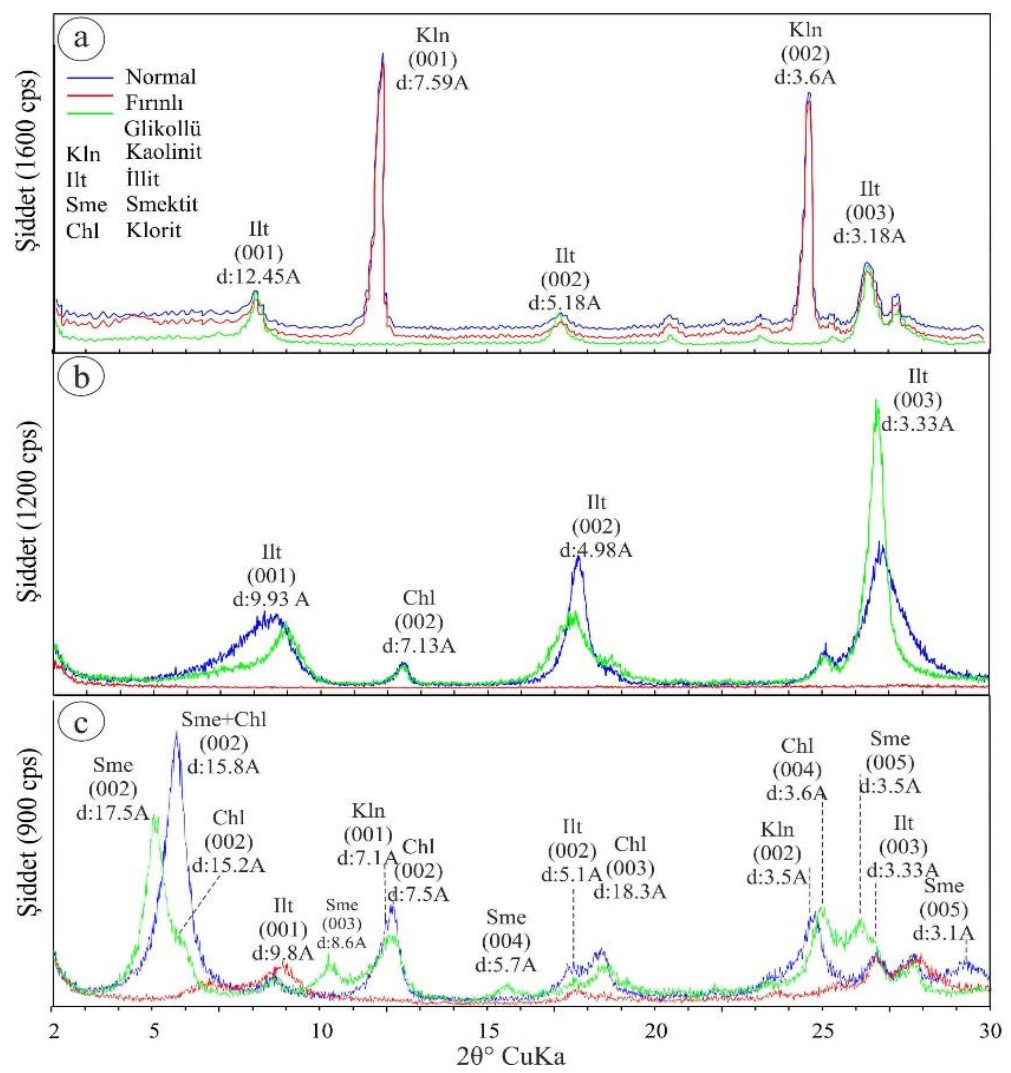

Şekil 6. Kil ayrımı yapılan örneklerde XRD-KF çekimleri. (a) Geminbeli kaolin yatağından alınan kaolinit içeriği fazla olan altere örnek (No: GD-3). (b) İllit içeriği fazla olan altere örnek (No: GD-27). (c) Smektit/klorit içeren altere örnek (No: GD-23)
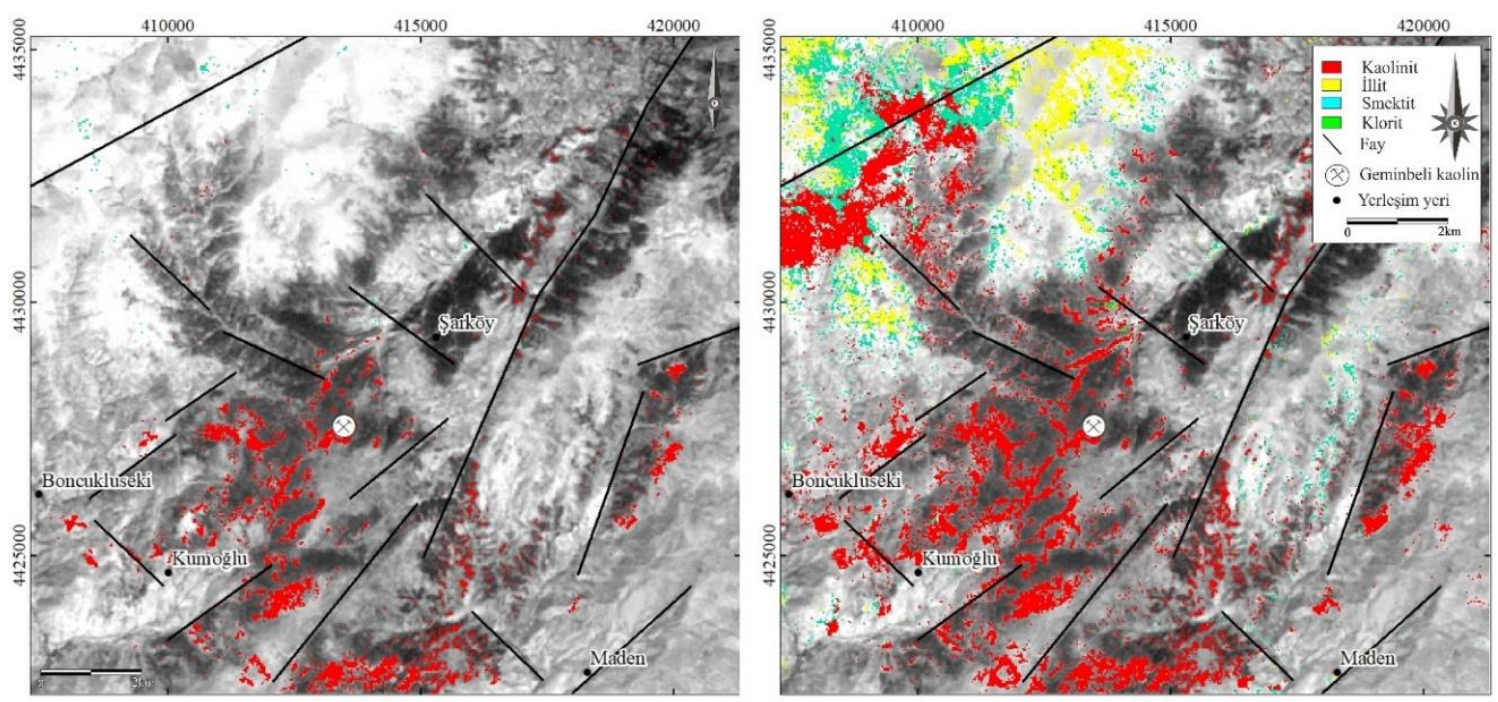

Şekil 7. Geminbeli kaolin yatağı ve çevresinin spektral sınıflandırma yöntemleri ile kil minerallerinin coğrafik konumları ve uzaysal dağılımları. (a) SAM sonuçları. (b) MF sonuçları

\section{Tartışma ve Sonuçlar}

İnceleme alanı içerisinde yoğun bitki örtüsünün hakim olması nedeniyle spektral siniflamalarda negatif yönde bir etki göstereceği düşünülmüş olup bu alanlara analizler sirasinda maskeleme uygulanmıştır. ASTER uydusu VNIR bantlarının kombinasyonu ile oluşturulmuş görüntüde işletilen kaolin sahası ile çevresinde gözlenen killeşme alanları aynı renk tonlarında gözlenmektedir (Şekil 8). Bu görüntü dikkate alınırsa, görüntüdeki bütün beyazımsı renkli alanların kaolin sahası olması beklenir. Fakat arazi ve laboratuvar çalışmaları, bu alanlarda kaolinit ile birlikte illit, smektit ve klorit türü killerin de dağılım gösterdiğini ortaya 
koymaktadır. Kil türlerindeki bu çeşitlilik killeşmeleri meydana getiren hidrotermal çözeltilerin yan kayaçlarda aynı oranlarda etkileşime girmediğini ve farklı değişimlere neden olduğunu göstermektedir. Çalışma alanında bu kil türlerine göre bir haritalama yapmak için mümkün olduğunca sık ve sistematik örnekleme yapılması gerekmektedir. Alınacak bu örneklerin her birinde XRD-KF çekimleri yapılıp elde edilen sonuçlara göre ancak bir kil dağılım haritası çıkarılabilecektir. Bu da uzun ve maliyetli bir süreci gerektirmektedir. $\mathrm{Bu}$ nedenle, uzaktan algilama teknolojisinden faydalanilarak bu haritalama işlemi gerçekleştirilmiştir.

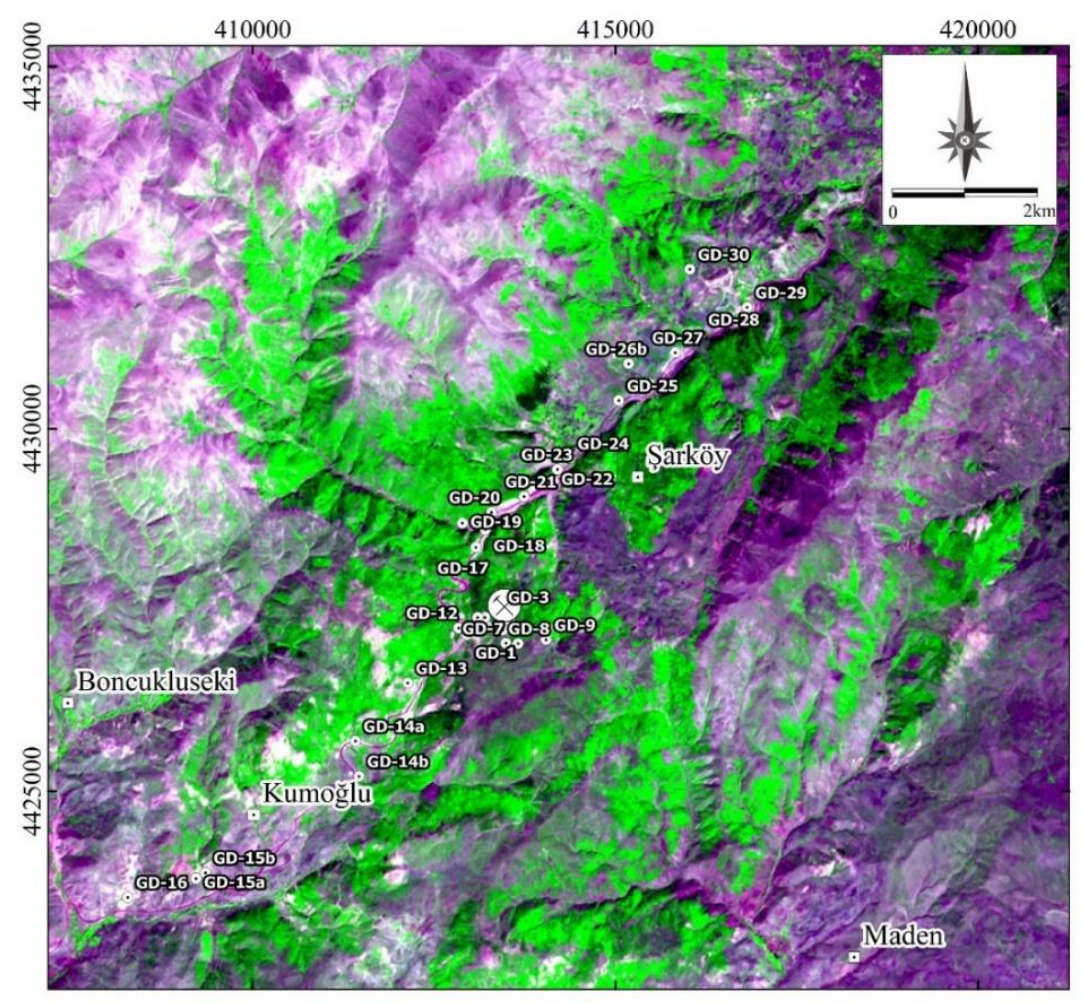

Şekil 8. VNIR bantlarının kombinasyonu ile oluşturulmuş arazi görünümü (K:VNIR1, Y:VNIR 3, M: VNIR 2

SAM ve MF sinıflandırma yöntemlerine ait sonuçlarda, 4 kil grubuna ait dağılım haritaları elde edilmiştir. Bu sonuçlara göre elde edilen kil türü dağılımları ile XRD-KF sonuçları karşılaştırıldığında, XRD sonuçlarında kaolinit içeriği yoğun olarak tespit edilen örneklerin elde edilen dağılım haritaları ile örtüştüğü görülmektedir. Aynı şekilde, yoğun illit içeren GD-27 nolu örnek lokasyonunun her iki sınıflandırmada elde edilen dağılım haritaları ile örtüştüğü görülmektedir. Klorit ve smektit içeren örneklerin XRD sonuçları ile MF sonuçları birbiri ile örtüşmekte olup SAM sonuçları ile örtüşmemektedir. Bu nedenle, MF yönteminin SAM yöntemine göre daha etkili ve detay sonuçlar verdiği söylenebilir.

XRD-KF sonuçları, örneklerde kaolinit, illit, klorit ve smektit türü killerinin birlikte bulunabileceğini göstermektedir. Bu nedenle, SAM ve MF siniflandırma yöntemlerinde elde edilen dağılım haritalarındaki kil türlerinin, bulundukları lokasyonlarda tek başlarına ve/veya diğer kil türleri ile birlikte bulunabileceği ihtimalini doğurmaktadır. Ayrıca, XRD sonuçlarında yoğun olan kil türlerinin sinıflandırma yöntemlerinde de baskın sonuçları verdiği tespit edilmiştir.

Sonuç olarak, kil tayini ve dağılımlarının ortaya çıkarılmasında SAM ve MF spektral sinıflandırma yöntemlerinden oldukça kullanışlı veriler elde edilmiştir. Bu verilerin, daha az maliyet ve daha kısa sürelerde mevcut işletilen kaolin sahasının geliştirilme aşamalarında ve yeni kaolin sahalarının tespit çalışmalarında önemli katkılar sunacağ 1 öngörülmektedir.

\section{Katkı Belirtme}

Bu çalışma, Cumhuriyet Üniversitesi, Bilimsel Araştırma Projeleri Birimi (CÜBAP) tarafından M-754 numaralı proje desteklenmiştir. 


\section{Kaynaklar}

Abrams, M. 2000. The Advanced Spaceborne Thermal Emission and Reflection Radiometer (ASTER): Data products for the high spatial resolution imager on NASA's Terra Platform. International Journal of Remote Sensing, 21(5), 847-859.

https://doi.org/10.1080/014311600210326

Abrams, M., ve Hook, S. J. 1995. Simulated Aster Data for Geologic Studies. IEEE Transactions on Geoscience and Remote Sensing, 33(3), 692699. https://doi.org/10.1109/36.387584

Abrams, M., ve Yamaguchi, Y. 2019. Twenty Years of ASTER Contributions to Lithologic Mapping and Mineral Exploration. Remote Sensing, 11(11), 1394. https://doi.org/10.3390/rs11111394

Archard, F., ve D’Souza, G. 1994. Collection and PreProcessing of NOAA-AVHRR $1 \mathrm{~km}$ Resolution Data for Tropical Forest Resource Assessment. Report EUR 16055, European Commission, Luxembourg, 56.

Ayoobi, I., ve Tangestani, M. H. 2017. Evaluating the Effect of Spatial Subsetting on Subpixel Unmixing Methodology Applied to ASTER Over a Hydrothermally Altered Terrain. International Journal of Applied Earth Observation and Geoinformation. 62, 1-7. https://doi.org/10.1016/j.jag.2017.05.008

Başıüyük, Z., 2006. Eosen Volkaniklerinin Hidrotermal Alterasyon MineralojisiPetrografisi ve Jeokimyas1: Zara-İmranl1Suşehri-Şerefiye Dörtgeni'nden Bir Örnek (Sivas Kuzeydoğusu, İç-Doğu Anadolu, Türkiye). Doktora Tezi, Sivas Cumhuriyet Üniversitesi Fen Bilimleri Enstitüsü, Sivas, 299s.

Boardman, J. W., 1998. Leveraging the High Dimensionality of AVIRIS Data for ImprovedSubpixel Target Unmixing and Rejection of False Positives: Mixture Tuned Matched Filtering.'InProceedings of the 5th JPL Geoscience Workshop, edited by R. O. Green, Pasadena, CA: NASA Jet Propulsion Laboratory 55-56.

Boztuğ, D., 2008. Petrogenesis of The Kösedag Pluton, Suşehri-NE Sivas. Turkish Journal of Earth Sciences, 17, 241-262.

Canbaz, O., Gürsoy, Ö. ve Gökce, A., 2018. Detecting Clay Minerals in Hydrothermal Alteration Areas with Integration of ASTER Image and Spectral Data in Kösedag-Zara (Sivas), Turkey. Journal of Geological Society of India, 91(4), 389-516.
Clark, R. N. 1999. Spectroscopy of Rocks and Minerals and Principles of Spectrocopy. Remote Sensing for the Earth Sciences: Manual of Remote Sensing, Ed.: Rencz, A.N.). John Wiley and Sons, New York, 3-58.

Efe, A. ve Gökce, A., 1999. Geology and Fluid Inclusion Studies of the Maden Village (Imranli-Sivas) $\mathrm{Pb}-\mathrm{Zn}$ Deposits. Bulletin of Faculty of Engineering of Cumhuriyet University, Series-Earth Sciences, 16, 29-38.

Eyuboglu, Y., Dudas, F. O., Thorkelson, D., Zhu, D. C., Liu, Z., Chatterjee ve N., Santosh, M., 2017. Eocene Granitoids of Northern Turkey: Polybaric Magmatism in an Evolving Arc-Slab Window System. Gondwana Research, C. 50, 311-345.

https://doi.org/10.1016/j.gr.2017.05.008

Eva, H., ve Lambin, E. F. 1998. Burnt Area Mapping in Central Africa Using Atsr Data. International Journal of Remote Sensing, 19(18), 3473-3497. https://doi.org/10.1080/014311698213768

De Carvalho, O. A., ve Meneses, P. R. 2000. Spectral Correlation Mapper (SCM); An Improvement on the Spectral Angle Mapper (SAM). Summaries of the 9th JPL Airborne Earth Science Workshop, JPL Publication 00-18, 9 p

Gad, S., ve Kusky, T. 2007. ASTER Spectral Ratioing for Lithological Mapping in the Arabian-Nubian Shield, the Neoproterozoic Wadi Kid Area, Sinai, Egypt. Gondwana Research, 44, 196-202. https://doi.org/10.1016/j.gr.2006.02.010

Girouard, G., ve Bannari, a. 2004. Validated Spectral Angle Mapper Algorithm for Geological Mapping: Comparative Study Between QuickBird and Landsat-TM. XXth ISPRS Congress Istanbul, 599-604.

Gupta, R. P. 2003. Remote Sensing Geology. Berlin. Springer, 415.

Harsanyi, J. C., ve Chang, C. I. 1994. Hyperspectral Image Classification and Dimensionality Reduction: An Orthogonal Subspace Projection Approach. IEEE Transactions on Geoscience and Remote Sensing, 32(4), 779-785. https://doi.org/10.1109/36.298007

Hawkesworth, C. J., Turner, S. P., McDermott, F., Peate, D. W. ve Van Calsteren, P., 1997. U-Th Isotopes in Arc Magmas: Implications for Element Transfer From the Subducted Crust. Science, 276(5312), 551-555. https://doi.org/10.1126/science.276.5312.551

Hu, B., Xu, Y., Wan, B., Wu, X., ve Yi, G. 2018. Hydrothermally Altered Mineral Mapping Using Synthetic Application of Sentinel-2A MSI, ASTER and Hyperion data in the Duolong 
Area, Tibetan Plateau, China. Ore Geology Reviews, 101, 384-397. https://doi.org/10.1016/j.oregeorev.2018.07.017

Hunt, G. R. 1977. Spectral Signatures of Particulate Minerals in The Visible and Near Infrared. Geophysics, $\quad 42(3), \quad 501$. https://doi.org/10.1190/1.1440721

Iwasak1, A., ve Tonoka, H. 2005. Validation of A Crosstalk Correction Algorithm 371 for ASTER/SIWR. Transactions on Geoscience and Remote Sensing, 43, 2747-2751.

Kalkancı, Ş., 1974. Etüde Geologique et Petrochimique $\mathrm{du}$ Sud de la Region de Suşehri. Geochronologie du Massif Syenitique de Kösedağ (Sivas Turquie). These de Doctoral de 3 e Cycle, L'Universite de Grenoble, 135.

Kruse, F. A. 2012. Mapping Surface Mineralogy Using Imaging Spectrometry. Geomorphology, 137(1), 41-56.

https://doi.org/10.1016/j.geomorph.2010.09.032

Kruse, F. A., ve Perry, S. L. 2013. Mineral Mapping Using Simulated Worldview-3 Short-WaveInfrared İmagery. Remote Sensing, 5(6), 26882703. https://doi.org/10.3390/rs5062688

Mahanta, P., ve Maiti, S. 2018. Regional Scale Demarcation of Alteration Zone Using Aster Imageries in South Purulia Shear Zone, East India: Implication for Mineral Exploration in Vegetated Regions. Ore Geology Reviews, 102, 846-861.

https://doi.org/10.1016/j.oregeorev.2018.07.028

Malayoğlu, U. ve Akar, A., 1995. Killerin Sinıflandırmasında ve Kullanım Alanlarının Saptanmasında Aranan Kriterlerin İrdelenmesi. Endüstriyel Hammaddeler Sempozyumu, 21-22 Nisan 1995, İzmir, Bildiri Özleri Kitabı, s. 125132.

Massironi, M., Bertoldi, L., Calafa, P., Visonà, D., Bistacchi, A., Giardino, C. ve Schiavo, A., 2008. Interpretation and Processing of ASTER Data for Geological Mapping and Granitoids Detection in the Saghro Massif (Eastern AntiAtlas, Morocco). Geosphere, 4(4), 736-759. https://doi.org/10.1130/GES00161.1

Mehr, G., S., Ahadnejad, V., Abbaspour, R. A., ve Hamzeh, M. 2013. Using the mixture-tuned matched filtering method for lithological mapping with Landsat TM5 images. International Journal of Remote Sensing, 34(24), 8803-8816. https://doi.org/10.1080/01431161.2013.853144

MTA., 2002. 1/500.000 Türkiye Jeoloji Haritası, Sivas Paftasi. Maden Tetkik ve Arama Genel Müdürlüğü. Ankara.
Okay, A. I., ve Tüysüz, O., 1999. Tethyan Sutures of Northern Turkey. Geological Society, London, Special Publications, 156 (1), 475-515. https://doi.org/10.1144/GSL.SP.1999.156.01.22

Pirajno, F. 2009. Hydrothermal Processes And Mineral Systems, $1241 . \quad$ Springer. https://doi.org/10.1007/978-1-4020-8613-7

Pour, A. B., ve Hashim, M. 2012. The Application of ASTER Remote Sensing Data to Porphyry Copper and Epithermal Gold Deposits. Ore Geology Reviews, 44, 1-9. https://doi.org/10.1016/j.oregeorev.2011.09.009

Rajendran, S., ve Nasir, S. 2018. Mapping Of Hydrothermal Alteration in The Upper MantleLower Crust Transition Zone of The Tayin Massif, Sultanate of Oman Using Remote Sensing Technique. Journal of African Earth Sciences, 150, 722-743. https://doi.org/10.1016/j.jafrearsci.2018.10.001

Rowan, L. C., Mars, J. C. ve Simpson, C. J., 2005. Lithologic Mapping of the Mordor, NT, Australia Ultramafic Complex by Using the Advanced Spaceborne Thermal Emission and Reflection Radiometer (ASTER). Remote Sensing of Environment, 99(1-2), 105-126. https://doi.org/10.1016/j.rse.2004.11.021

Salehi, T., ve Tangestani, M. 2020. Evaluation of WorldView-3 VNIR and SWIR Data for Hydrothermal Alteration Mapping for Mineral Exploration: Case Study from Northeastern Isfahan, Iran. Natural Resources Research, (online paper). https://doi.org/10.1007/s11053020-09703-6

Yamaguchi, Y., Kahle, A. B., Tsu, H., Kawakami, T., ve Pniel, M. 1998. Overview of Advanced Spaceborne Thermal Emission and Reflection Radiometer (ASTER). IEEE Transactions on Geoscience and Remote Sensing, 36(4), 10621071. https://doi.org/10.1109/36.700991

Yang, R., Li, Z., ve Chen, X. 2012. Information Extraction of Typical Alteration Mineral Assemblage in Porphyry Copper Using ASTER Satellite Data, Arequipa Province of South Peru. Geo-information Science, 14(3), 411-418. https://doi.org/10.3724/sp.j.1047.2012.00411

Yılmaz, A., Okay, A. ve Bilgiç, T., 1985. Yukarı Kelkit Çayı Yöresi ve Güneyinin Temel Jeoloji Özellikleri ve Sonuçları: MTA Rapor No: 7777 (Yayınlanmamış), Ankara.

URL-1, https://www.mta.gov.tr/v3.0/bilgimerkezi/seramik-killer.(06.08.2020). 